\title{
Polymer-Supported Chiral Lewis Base Catalysts
}
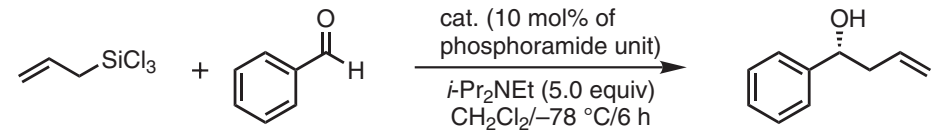

1: $84 \%$ yield, $63 \%$ ee

2: $43 \%$ yield, $40 \%$ ee<smiles>CN(Cc1ccc(C(CC(C)(C)C)C(C)(C)C)cc1)P1(=O)N(C)[C@@H]2CCCC[C@H]2N1C</smiles>

3: $35 \%$ yield, $45 \%$ ee

4: $36 \%$ yield, $60 \%$ ee

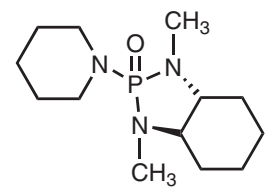

Significance: Novel polymer-supported chiral phosphoramides were used as a Lewis base catalyst $\mathbf{1}$ in the asymmetric addition of allyltrichlorosilane to benzaldehyde. The allylation of benzaldehyde proceeded in the presence of the catalyst $\mathbf{1}$ (10 mol\% of phosphoramide unit) at $-78^{\circ} \mathrm{C}$ for six hours in dichloromethane to give 1-phenyl-but-3en-1-ol in up to $84 \%$ yield with enantiomeric excesses of $63 \%$. The reaction was accelerated by the addition of five equivalents of ethyldiisopropylamine. Catalyst $\mathbf{1}$ was found to be more effective its homogeneous counterpart.
Comment: This is the first report on the synthesis of polymers having chiral phosphoramides and their catalytic applications in asymmetric addition of allyltrichlorosilane to benzaldehyde. 